\title{
Montgomery and informed consent: where are we now?
}

\author{
(c) (1) Q OPEN ACCESS
}

The Montgomery case in 2015 was a landmark for informed consent in the UK. Two years on, Sarah
Chan and colleagues discuss the consequences for practising doctors

\author{
Sarah W Chan chancellor's fellow ${ }^{1}$, Ed Tulloch MBChB student ${ }^{2}$, E Sarah Cooper consultant \\ obstetrician $^{3}$, Andrew Smith $Q C^{4}$, Wojtek Wojcik consultant liaison psychiatrist ${ }^{5}$, Jane E Norman \\ professor of maternal and fetal health and director of Tommy's Centre for Maternal and Fetal Health \\ 6
}

${ }^{1}$ Usher Institute for Population Health Sciences and Informatics, University of Edinburgh, Edinburgh, UK; ${ }^{2}$ Edinburgh Medical School, University of Edinburgh; ${ }^{3}$ Simpson Centre for Reproductive Health, Royal Infirmary of Edinburgh; ${ }^{4}$ Compass Chambers, Edinburgh; ${ }^{5}$ Department of Psychological Medicine, Royal Infirmary of Edinburgh; ${ }^{6} \mathrm{MRC}$ Centre for Reproductive Health, University of Edinburgh

The Montgomery $v$ Lanarkshire case of March $2015^{1}$ drew fresh attention to informed consent. Nadine Montgomery, a woman with diabetes and of small stature, delivered her son vaginally; he experienced complications owing to shoulder dystocia, resulting in hypoxic insult with consequent cerebral palsy. Her obstetrician had not disclosed the increased risk of this complication in vaginal delivery, despite Montgomery asking if the baby's size was a potential problem. Montgomery sued for negligence, arguing that, if she had known of the increased risk, she would have requested a caesarean section. The Supreme Court of the UK announced judgment in her favour in March 2015. The ruling overturned a previous decision by the House of Lords, ${ }^{2}$ which had been law since at least the mid 1980s. ${ }^{3}$ It established that, rather than being a matter for clinical judgment to be assessed by professional medical opinion, a patient should be told whatever they want to know, not what the doctor thinks they should be told.

Many organisations (in particular the General Medical Council, who intervened to make submissions in the case) said that the Montgomery decision had simply enabled UK law to catch up with current GMC guidance; others hailed it "the most important UK judgment on informed consent for 30 years." ${ }^{.4}$ Doctors have expressed their concerns about its potentially radical effects on patient care and clinical practice. ${ }^{5} \mathrm{We}$ held a public debate in 2015, including doctors, lawyers, and medical students, which showed renewed tension between the professional discretion of doctors and patients' choices ${ }^{6}$; indeed, the verdict has been characterised as supporting patient autonomy over medical paternalism. ${ }^{3-9}$ But what are the implications for doctors' practice and their legal liability? Two years after the Supreme Court's decision, we examine the effects of the Montgomery ruling on clinical and medicolegal practice.

\section{Response to the ruling}

Some clinicians said that retrospective application of the judgment could "open the floodgates" for claims in relation to doctors' past actions. ${ }^{10}$ Others thought that the Montgomery ruling was unlikely to have this effect, however "excited the claimant law firms might become initially."11 Legal opinions were reserved, describing the ruling as "the belated obituary, not the death knell, of medical paternalism." ${ }^{22}$ Some argued that the standard imposed by the Montgomery decision merely reflected good practice as already specified by the $\mathrm{GMC}^{13}$ and would make little practical difference to clinicians. ${ }^{8}$

Nevertheless, the concern generated by the ruling might affect doctors' behaviour and other potential cases. Others have raised questions about the implications for the legal treatment of clinical judgment, suggesting that it represents "a radical move away from English law's traditional respect for clinical expertise." $" 9$

Doctors at the coalface have received little official direction on how their practice should change in light of the ruling. We have heard anecdotally that some hospitals are in the process of updating their procedures on informed consent, but few have completed this. Although the Medical Defence Union and the Medical Protection Society have each issued statements and updated their guidance, as have some royal colleges (such as the Royal College of Surgeons), other bodies such as the GMC and the Royal College of Obstetricians and Gynaecologists (RCOG) have yet to do so.

RCOG's difficulty in providing guidance perhaps reflects the unique nature of obstetrics — essentially helping two patients through a normal and inevitable physiological process. A further challenge is that the risks of birth can change dramatically and 
quickly, making detailed discussion and informed decision making difficult. These "emergencies" might be exempt from the Montgomery ruling, depending on their nature and timing, but complications of labour (such as sudden and profound fetal distress or major maternal haemorrhage) are not, even though, as was noted in the judgment, choices about management of labour cannot generally be deferred. GMC guidance says that the consenting process is not a snapshot but an ongoing process. Planning for labour emergencies is essential, so that the doctor and patient can discuss the patient's wishes if an emergency should arise.

RCOG has proposed pilot programmes to identify what resources women, clinicians, and health services need to comply with the Montgomery ruling. Training and educational materials must be fit for purpose. Obstetricians urgently need guidance.

\section{Legal consequences for doctors}

The Montgomery decision redefined the standard for informed consent and disclosure. Previously, the Bolam tes ${ }^{14}{ }^{\text {in England }}$ and the Hunter $v$ Hanley test ${ }^{15}$ in Scotland were used to determine what should be disclosed. These tests ask whether a doctor's conduct would be supported by a responsible body of clinicians. The Bolam test was affirmed in Sidaway $v$ Bethlem Royal Hospital Governors and others, ${ }^{2}$ although the ruling was not unanimous, with judges placing different weight on the patient's right to make informed treatment decisions versus the doctor's professional judgment in disclosing information. The Montgomery case firmly rejected the application of Bolam to consent, establishing a duty of care to warn of material risks. The test of materiality defined in the Montgomery ruling was whether "a reasonable person in the patient's position would be likely to attach significance to the risk, or the doctor is or should reasonably be aware that the particular patient would be likely to attach significance to it." "The solicitor representing Montgomery spoke of the decision as having "modernised the law on consent and introduced a patient focused test to UK law." 16

\section{Retrospective cases}

Constitutionally, the Supreme Court cannot make new law; it can only state what, in theory, the law has always been. Doctors may have been treating patients as they understood the law to be, as in the Sidaway case, but the Supreme Court has told us that this was wrong ${ }^{3}$ and that anyone who practised according to Sidaway was also wrong.

In practical terms, the ruling should apply at least back to 1999 , when Montgomery saw her obstetrician. Guidance in effect at that time from the GMC, ${ }^{17} \mathrm{BMA},{ }^{18} \mathrm{NHS}$, and the Scottish Office ${ }^{19}$ supported a doctor's duty to disclose relevant information and risks. So the Montgomery principles have been known-or should have been known—by doctors for many years.

Since the Montgomery ruling, several attempts have been made to introduce a consent based claim to cases that were under way before the decision. One such attempt in Scotland has, so far, been unsuccessful. ${ }^{20}$ Two English cases have allowed consent claims to be added after the Montgomery decision. ${ }^{21}{ }^{22}$ Some cases have succeeded on a Montgomery basis ${ }^{23}$; we (AA) understand that others have settled before litigation ever started or was concluded, as the claims were unanswerable in the light of Montgomery. We (ESC) have noticed that a considerable proportion of cases of obstetric negligence raised since Montgomery involve consent in addition to standard complaints of substandard care. These issues are not always pursued, but obstetric litigation practice has noticeably changed, making professional training and clarity with respect to guidelines an even higher priority.

\section{Subsequent cases}

Looking at some of the cases in which the Montgomery ruling has been considered tells us about its interpretation to date. In Spencer $v$ Hillingdon NHS Trust (April 2015) ${ }^{23}$ the patient had bilateral pulmonary emboli after a hernia operation. He did not seek treatment immediately because he had not been advised of the risk of deep vein thrombosis or pulmonary embolism or of symptoms that might indicate these. The judge considered the Montgomery ruling and found that failure to inform the patient was a breach of the duty of care.

Shaw $v$ Kovac (October 2015) ${ }^{24}$ concerned a patient who died in 2007 after a transaortic valve implantation, which was then still the subject of clinical trials and not fully approved. The claimant's argument sought to use the Montgomery ruling to ground a claim for damages for the loss of life without informed consent. The court rejected this, holding that the Montgomery ruling did not create a right to informed consent as an independent cause of action, but simply set a new legal standard for the duty to disclose.

In Mrs A $v$ East Kent Hospitals University NHS Foundation Trust (April 2015), ${ }^{25}$ the claimant's baby, who was conceived using intracytoplasmic sperm injection, had a chromosomal abnormality. The claimant alleged that the trust was negligent in failing to advise of this possibility. The court applied the Montgomery test and decided that the risk was not material, because neither a reasonable patient nor the patient herself would have attached significance to it. Thus, although the test is focused on patients, doctors are not liable for every omission of disclosure to which a patient later objects." 25

\section{Clinical concerns and ethical arguments}

Some doctors feared that more stringent disclosure requirements would risk overwhelming patients with information, causing distress or leading them to make poor decisions, while doctors' time would be taken up with lengthy explanations, creating a drain on healthcare resources. Information overload is unlikely given that information should be tailored to the patient. But doctors must judge what is appropriate for each patient and how their exercise of judgment might be assessed by the courts. The doctor might think that disclosure of certain information could lead the patient to a decision that is not in their best interests, as was true for the Montgomery case. But the ethical and legal position is clear: doctors must not withhold information simply because they disagree with the decision the patient is likely to make if given that information.

Making sure that patients understand all the information they need to make a decision will inevitably take longer. But allocation of health resources should be tackled systematically rather than individually. Healthcare policy should cover, for example, which treatments should be available and how consent procedures should be handled. ${ }^{17}$ The doctor's duty is simply to treat patients according to their interests, which might include being given more information than usual.

A second concern was that the ruling would encourage "defensive medicine," shifting the focus from helping the patient to protecting the doctor. But doctors should have already been following GMC guidance, which highlights the importance of communication. $^{13}$ 
Finally, doctors criticised the focus of patient autonomy over medical paternalism. But this is a false dichotomy - the idea of a fully autonomous patient making choices completely independent of the doctor's input does not reflect the complex reality of medical decision making, nor does the caricature of a paternalistic doctor riding roughshod over patients' objections. Patients are not always aware of the facts of their treatment after consent related discussions,${ }^{26}$ and they are influenced by the way in which information is presented (the "framing effect"). ${ }^{27}$ But the difficulties of conveying information about treatment and risks should not be taken to indicate that patients are incapable of understanding medical information or that patient autonomy in decision making is meaningless. Rather it shows that the communication process has a strong influence on how patients understand, remember, and evaluate information-all of which are essential to informed consent. The doctor's role is to ensure that relevant information is presented to enable the patient to use it meaningfully.

\section{Conclusions}

The Montgomery case was framed as a clash of values_-patient autonomy versus medical paternalism. In reality, medical decision making involves a nuanced negotiation of information. Today's patients can expect a more active and informed role in treatment decisions, with a corresponding shift in emphasis on various values, including autonomy, in medical ethics.

The full implications of the case are undoubtedly still unknown, but Montgomery has clear relevance for medical law and ethics. Legally, consent law has been clarified and aligns with current GMC guidance, and the Montgomery test has already been applied in several cases. Ethically, it clarifies the existing shift towards a more cooperative approach in the consultation room. The Montgomery ruling has not radically changed the process of consent; it has simply given appropriate recognition to patients as decision makers.

Montgomery v Lanarkshire Health Board [2015] SC 11 [2015] 1 AC 1430. Sidaway v Board of Governors of the Bethlem Royal Hospital and others [1985] 871 AC Heywood R. RIP Sidaway: patient-oriented disclosure-a standard worth waiting for? Montgomery v Lanarkshire Health Board[2015] UKSC 11. Med Law Rev 2015;23:455-66. doi:10.1093/medlaw/fwv024pmid:26023076.

4 Dyer C. Doctors should not cherry pick what information to give patients, court rules. BMJ 2015;350:h1414. doi:10.1136/bmj.h1414pmid:25769489.

5 Sundar S. New law on consent will overload seriously ill patients. BMJ 2015;350:h1787. doi:10.1136/bmj.h1787pmid:25851299.

6 University of Edinburgh. Patient consent: do doctors really know best? https://youtu.be/ ICWOYz UJLC.

7 Edozien LC. UK law on consent finally embraces the prudent patient standard. BMJ 2015;350:h2877. doi:10.1136/bmj.h2877pmid:26023049

8 Farrell AM, Brazier M. Not so new directions in the law of consent? Examining Montgomery v Lanarkshire Health Board. J Med Ethics 2016;42:85-8. doi:10.1136/medethics-2015102861pmid:26685149.

9 Montgomery J, Montgomery E. Montgomery on informed consent: an inexpert decision?J Med Ethics 2016;42:89-94. doi:10.1136/medethics-2015-102862pmid:26811487.
10 Sundar S. Case based laws are turning into "emperors new clothes."[electronic response to Sokol DK. Update on the UK law on consent] BM.http://www.bmj.com/content/350/ bmj.h1481/rr-23.

11 Weston A. Consent down under. Br Dent J2015;219:304. doi:10.1038/sj.bdj.2015.764pmid: 26450228.

12 Foster C. The last word on consent? New Law J 2015;165:1.

13 Sokol DK. Update on the UK law on consent. BMJ 2015;350:h1481. doi:10.1136/bmj. h1481pmid:25779588.

14 Bolam v Friern Hospital Management Committee [1957] 1 WLR 582.

15 Hunter v Hanley 1955 SC 200.

16 Tyler F. Supreme Court decision changes doctor-patient relationship forever. Balfour and Manson, 2015.

17 General Medical Council. Good Medical Practice. 1995

18 British Medical Association. The Handbook of Medical Ethics. British Medical Association, 1981.

19 Scottish Office. The Patient's Charter: What Users Think. 1992. Scottish Office, 1993.

20 Clark v Greater Glasgow Health Board [2016] CSOH 25. A further judgment was issued in this case on appeal which refused the amendment. It is understood that an application to appeal to the Supreme Court is being presented and if allowed, some of the issues raised in this article may be further discussed.

21 Jones v Royal Wolverhampton NHS Trust [2015] EWHC 2154 (QB).

22 Georgiev v Kings College Hospital NHS Foundation Trust [2016] EWHC 104 (QB).

23 Spencer v Hillingdon Hospital NHS Trust [2015] EWHC 1058 (QB).

24 Shaw v Kovac [2015] EWHC 3335 (QB).

25 Mrs A v East Kent Hospitals University NHS Foundation Trust [2015] EWHC 1038 (QB).

26 Byrne DJ, Napier A, Cuschieri A. How informed is signed consent? Br Med J (Clin Res Ed) 1988:296:839-40. doi:10.1136/bmj.296.6625.839pmid:3130937.

27 McNeil BJ, Pauker SG, Sox HC Jr, , Tversky A. On the elicitation of preferences for alternative therapies. N Engl J Med 1982;306:1259-62. doi:10.1056/ NEJM198205273062103pmid:7070445.

Contributors and sources: The authors were organisers (ET, WW, JEN) and participants (SWC, AS, ESC) of an event in the Edinburgh Medical Debates series on the ethical and legal impact of the Montgomery case. ${ }^{6}$ ET is a medical student at the University of Edinburgh and was primarily responsible for research and initial drafting of the manuscript; SWC is a researcher in bioethics and was responsible for subsequent drafting, critical revisions, ethical analysis, and part of the legal research; ESC, WW, and JEN are clinicians and were responsible for conceiving the idea for the manuscript, critical revisions, and obstetric medicolegal advice; AS is a barrister and QC in both Scotland and England, specialising in medical negligence, and was responsible for legal advice, analysis, and critical revisions. All authors approved the submission of the manuscript. SWC and JEN are the guarantors.

Competing interests: We have read and understood BMJ policy on declaration of interests and declare the following interests: AS represented the GMC in the Supreme Court in the Montgomery case. All other authors have nothing to declare.

Provenance and peer review: Not commissioned; externally peer reviewed

\section{Accepted: 05052017}

Published by the BMJ Publishing Group Limited. For permission to use (where not already granted under a licence) please go to http://group.bmj.com/group/rights-licensing/ permissions

This is an Open Access article distributed in accordance with the Creative Commons Attribution Non Commercial (CC BY-NC 4.0) license, which permits others to distribute, remix, adapt, build upon this work non-commercially, and license their derivative works on different terms, provided the original work is properly cited and the use is non-commercial. See: http://creativecommons.org/licenses/by-nc/4.0/ . 